\title{
Public health effects of gambling - debate on a conceptual model
}

\author{
Tiina Latvala', Tomi Lintonen ${ }^{1 *}$ (D) and Anne Konu²
}

\begin{abstract}
Background: Gambling for money is a popular leisure time activity in most countries, which has major social and economic impacts not only affecting the gambler, but his/her significant others, and the society. Gambling impact studies can help researchers and policymakers compare the health and social costs and benefits of different gambling policies and can be used when considering which gambling policies will reduce or increase costs or benefits the most. In a public health approach, the impacts of gambling, negative and positive, are assessed across the entire severity spectrum of the activity. Although some studies have created basic principles for conducting impact studies, a theoretical model is currently lacking. The aim of this debate is to review complementing and contrasting views on the effects of gambling to create a conceptual model, where a public health perspective is applied.

Main text: The effects of gambling can be structuralized using a conceptual model, where impacts are divided into negative and positive; costs and benefits. Costs and benefits are categorized into three classes: financial, labor and health, and well-being. These classes manifest in personal, interpersonal, and societal levels. Individual impacts cause effects on a personal level to gamblers themselves. External impacts influence the interpersonal and society/ community levels and concern other people. The temporal level refers to the development, severity and scope of the gambling impact. These include general impacts, impacts of problem gambling and long-term impacts of gambling.

Conclusions: The conceptual model offers a base on which to start building common methodology for assessing the impact of gambling on the society. While measuring monetary impacts is not always straightforward, the main issue is how to measure the social impacts, which are typically ignored in calculations, as are personal and interpersonal impacts. The reviewed empirical work largely concentrated on the costs of gambling, especially costs on the community level. The Model can be used to identify areas where research is scarce. Filling the gaps in knowledge is essential in forming a balanced evidence base on the impacts of gambling. Ideally, this evidence could be the starting point in formulating public policies on gambling.
\end{abstract}

Keywords: Public health, Gambling, Conceptual model

\section{Background}

Gambling can be defined as betting money on an outcome of uncertain results to win money. All forms of gambling, even those typically considered to be more skill-based, like poker and sports betting, contain an element of luck [1]. Another common characteristic of gambling is that it is a zero-sum game: when one player wins, the other must lose [2]. Gambling is a popular leisure time activity in most countries, and the vast majority of adults have engaged in some gambling activity at least once in their life,

\footnotetext{
* Correspondence: tomi.lintonen@alkoholitutkimussaatio.fi

${ }^{1}$ Finnish Foundation for Alcohol Studies, P.O. Box 30, FI-00271 Helsinki, Finland

Full list of author information is available at the end of the article
}

and between 40 and $80 \%$ have participated in some form of gambling in the last 12 months [3]. For most individuals, gambling is a form of entertainment $[4,5]$. For some consumers, the motivation for gambling is influenced by social interactions because gambling venues offer social settings to meet people [6,7], whereas others are mainly motivated by the dream of winning money [8]. By contrast, some use gambling to escape their problems, and this is especially common among problem gamblers [9].

Gambling is typically viewed as a continuum, with most people gambling only occasionally or not at all and some gambling more frequently. Along this continuum, people can experience negative financial and social consequences, although harms tend to be more common

(c) The Author(s). 2019 Open Access This article is distributed under the terms of the Creative Commons Attribution 4.0 International License (http://creativecommons.org/licenses/by/4.0/), which permits unrestricted use, distribution, and 
among frequent gamblers [10]. Based on harms experienced because of gambling, gamblers are usually divided to recreational, at-risk, and problem and pathological gamblers [11, 12]. Problem and pathological gamblers are usually called problematic gamblers. Pathological gambling is a disorder included in both diagnostic manuals: International Classification of Disorders [13] and Diagnostic and Statistical Manual [14]. Prevalence of problem and pathological gambling varies between countries, but it is estimated that among adult population 1 to $4 \%$ are problem gamblers [15], whereas prevalence estimates of pathological gambling range from 0.1 to $0.8 \%$ [16]. There are, however, much more people suffering from gambling-related harms.

Harms caused by gambling can co-occur with other difficult situations in life, usually intensifying along with crises and continuing even after the problematic behavior comes to an end [17, 18]. Gambling-related harm can affect multiple domains of life [17], including financial [19, $20]$ and health problems [21, 22], psychological and emotional distress [23, 24], and impaired social and cultural relationships [25-27]. They have an influence on multiple levels: gambling-related harms restrict the gambler and their family, friends, workplace, community, and society $[17,18,28,29]$. Because of these significant influences on society and the population's overall health, gambling is a critical public health issue [30, 31].

The impacts of gambling on societies is positive and negative and depends on a number of factors, including what type of gambling environments and games are available, how long gambling has been possible, whether gambling revenues are derived locally or outside the jurisdiction, and the effectiveness of gambling policy [32-35]. Overall, there are several main purposes for conducting impact studies on gambling. First, to demonstrate that gambling has major social and economic impacts. Impact studies can also help researchers and policymakers compare the impact of different health and social problems and benefits; for example, gambling impacts can be weighed against alcohol impacts. Additionally, impact studies can be used when considering which gambling policies will reduce or increase costs or benefits the most [36].

Different approaches have been used to study the impacts of gambling. Research into the socioeconomic impacts of gambling can be conducted from a cost of illness perspective, commonly used in alcohol and drug research; however, this approach neglects the benefit side [37]. Economic cost-benefit analysis (CBA) measures changes in well-being in common units (dollars) [38] and attempts to discover whether increased gambling opportunities are positive for society [39]. In this approach, monetary value is also assigned to intangible harms (harms not necessarily monetary in nature, e.g., the pain and suffering of problem gambler), and harms are known to affect others in addition to the gamblers themselves. This approach, however, has been criticized because an arbitrary monetary value is applied to these intangible harms $[37,40]$. Anielski and Braaten [39] also examined the impacts of gambling by using an approach they called full cost-benefit accounting, which attempts to overcome the obstacles of CBA. However, like Williams, Rehm and Stevens [32] stated, figures obtained by this approach are not reliable and somewhat arbitrary, and it is not clear how the monetary values for some variables are created. Anielski and Braaten [39] also described many other approaches to study gambling impacts.

In a public health approach, the impacts of gambling, negative and positive, are assessed across the entire severity spectrum of the activity [41]. According to the literature, harms can occur also among those classified as nonproblem gamblers [42]; however, examining only problem or pathological gambling and its impacts on society is still common in economic costing studies [43]. When concentrating solely on problematic gambling, only the tip of the iceberg is observed and gambling harms and its costs to society are underestimated [42]. Additionally, in a public health approach, the positive effects associated with gambling are recognized [17]. In the economic literature, gambling revenues and positive impacts on public services have been observed [32], but fewer studies have examined the positive impacts of gambling on gamblers or their significant others. In a public health approach, the negative impacts of gambling can be assessed by healthrelated quality of life (HRQL) weights, known as disability weights (DW), which measure the per-person burden of health state on quality of life $[44,45]$. DWs have been used to measure intangible social costs of gamblers, but could be also used to discover gambling harms that affect a gambler's social network. Some studies have attempted to quantify the benefits of gambling by "consumer surplus," which is the difference between what people would be willing to pay for a product or service versus what they pay [32]. In Australia, the estimated consumer surplus for gambling is AUS\$8-\$11 billion per year [2]. However, using this arbitrary monetary amount to quantify something that is clearly nonmonetary creates similar problems when trying to place a monetary value on the "social" impacts of gambling [32].

Since the expansion of the gambling market, the question of gambling impacts has piqued researchers and policymakers interest [37]. Despite increased interest in gambling impacts, no consensus has been reached regarding the appropriate theoretical and methodological approach to studying them [32]. A theoretical model is still lacking, although some studies have created basic principles for conducting socioeconomic impact studies. Based on Anielski and Braatan's socioeconomic impact of gambling (SEIG) framework [39], Williams et al. [32] proposed a simpler categorization of impacts. By doing this, Williams 
et al. ignored that impacts can be evaluated on different levels, like the individual, family, household, community, regional, and national levels.

Several limitations of earlier gambling impact studies have been highlighted $[37,40]$, but one major concern has been how to capture and quantify the social impacts [32, 46]. While quantifying the economic impacts is reasonably straightforward (e.g., costs of treating problem gamblers or of preventing problem gambling), this is not the case for social impacts (e.g., invisible costs like the impacts of emotional stress and relationship problems caused by gambling), which cover the major negative impacts from gambling and cannot be evaluated in monetary terms [42].

Thus, studies have mostly ignored social impacts, choosing to measure only the economic costs or benefits that are quite easily quantifiable. This approach, however, presents a very biased view of the situation. There are no established ways to define the social impacts of gambling. Based on Williams et al. [32] social impacts are costs or benefits that are nonmonetary in nature. Walker and Barnett [40] stated that social costs must aggregate societal real wealth, that is, cause harm to someone in the society and benefit no one. They also defined that social cost must be social, rather than personal.

According to these definitions, when a gambler becomes ill because of excessive gambling, their suffering should not be counted as a social cost as long as someone in society gains from this excessive gambling and gamblers do not demand any treatment that would cause costs to society. In our study, rather speaking of social impacts, we use the term nonmonetary impacts (i.e., nonmonetary costs and nonmonetary benefits). Costs and benefits refer to overall negative or positive gambling impacts and not only those with monetary value. We also state that impacts should be examined at the societal, individual, and interpersonal levels.

Compared with existing models, this model combines aspects from costing studies [32, 39] and from gambling harm literature [18, 33-35] making the present model more comprehensive and up to date. The Model emphasizes the public health perspective, which is somewhat different from the one in costing studies. It covers both positive and negative effects of gambling and examines costs and benefits on individual, interpersonal and community/society levels. The model includes a temporal dimension, which refers to the development and severity of gambling behavior. From the public health perspective, it is not presumed that costs and benefits result only from problem gambling; instead we are interested in the whole spectrum of gambling behavior. Costs and benefits can be general, come from problem gambling and/or can have long term effects. In summary, a common and comparable methodology for evaluating the impacts of gambling is necessary [32, 37], and none has been created. Studies have usually concentrated on impacts of problem gambling while ignoring the entire continuum of gambling. Additionally, the emphasis has been on economic costs, whereas most gambling costs are "social." The benefits of gambling are usually examined at the societal level (e.g., government revenue), and the influence of gambling on gamblers and their significant others are ignored. This debate argues for a conceptual theoretical model based on the gambling impacts literature, where a public health perspective is applied.

\section{Main text \\ Structure of the public health impacts of gambling (PHIGam) model}

Gambling impacts can be observed at the personal, interpersonal, and community/society levels (Fig. 1). Personal level refers to the gamblers themselves and interpersonal level to people close to the gambler: friends, family and work colleagues. Impacts can be individual or external. Individual impacts induce effects on a personal level to the gambler. External impacts influence the interpersonal and society/community levels and concern those who are not necessarily gamblers themselves. Gambling creates costs and benefits that others must pay for or can exploit. For example, gambler's increased debt and financial strain affects family members' lives, and the effects escalating into bankruptcy and homelessness can also be observed on the community level. Thus, it is of utmost importance that impacts are examined on multiple levels. In the model, impacts can be divided into negative and positive. However, impacts can simultaneously be both negative and positive. For example, gambling is linked to increased criminality [44] but can also decrease illegal gambling [45]. Similarly, tourism revenues are positive [46] but on the other hand tourism can increase crime [47].

In the model, benefits (Fig. 2) and costs (Fig. 3) are categorized into three classes: financial, labor and health, and well-being. These classes manifest on personal, interpersonal, and societal levels. Financial impacts, for example, include gambling revenues, tourism, impacts on other industries, and infrastructure cost or value change. On the personal and interpersonal levels, financial impacts can be changes in financial situations. Overall, financial impacts contribute to economic activity and economic growth. Labor impacts include gambling effects on work, such as changes in productivity, absenteeism, reduced performance, inability to work, job gains and losses, and unemployment. Health and well-being impacts include the effects that gambling has on physical, psychological, and social health and well-being.

Temporal level refers to the development, severity and scope of the gambling impact. These include general impacts, impacts of problem gambling and long-term impacts of gambling. General impacts usually result 


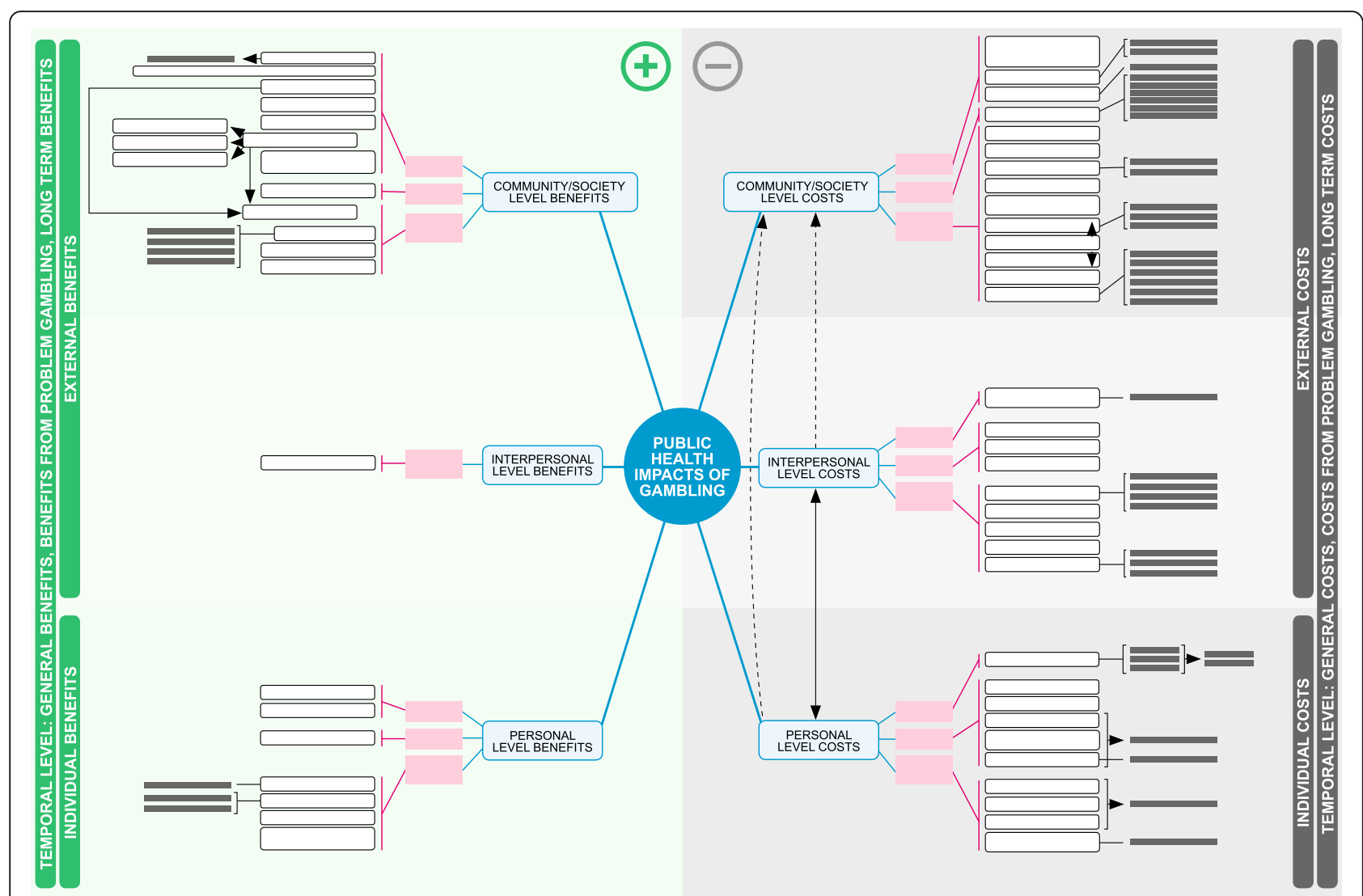

Fig. 1 The structure of the Public Health Impacts of Gambling (PHIGam) model

from non-problematic (recreational and at-risk gamblers) gambling. For example, gambling can be a leisure time option that takes time and money from other activities. Impacts of problem gambling are severe consequences that materialize on personal, interpersonal and community/society levels. For example, a problem gambler who uses a lot of money on gambling and falls into bankruptcy influences his/her family's financial situation and the society by creating cost (e.g. social care cost). These long-term effects of problem gambling can materialize even if the person no longer gambles; it can create a change in the life course of an individual, and even pass between generations [18]. On the positive side at society/community level, money spent on gambling increases gambling revenues, which in turn can have positive long-term effects when partly directed to beneficial causes, e.g. public services or environmental protection.

Personal and interpersonal level costs are mostly nonmonetary in nature, including invisible individual and external costs that are general, costs of problem gambling and long-term cost. Some of these invisible costs can turn into visible at the society/community level, for example, when gambler's family members seek help or treatment. Most of the time, however, these costs remain unrecognized. Society/community level external impacts are mostly monetary and are general costs/benefits, costs/benefits related to problem gambling and longterm cost/benefits.

\section{Personal level impacts Financial impacts}

Financial harms are common, especially among problem gamblers. A survey conducted in Queensland showed that $83 \%$ of problem gamblers had experienced gambling-related financial problems [47]. Another study observed that $34 \%$ of problem gamblers reported having severe financial difficulties, compared with $23 \%$ of at-risk gamblers and $10 \%$ of nongamblers [48]. In Finland, almost $8 \%$ of the population had experienced some sort of financial harms because of their gambling $[49,50]$, and among treatmentseeking gamblers, the percentage was $87 \%[50,51]$. Financial problems can range from escalating harms, such as diminishing savings and borrowing money, to major harms, such as bankruptcy or loss of all valuable possessions [17]. A study conducted among casino visitors observed that $65 \%$ of the "problem" players had to turn to others to relieve a desperate financial situation because of their gambling, whereas none of the "social" players had to do so. In addition, $52 \%$ of the "problem" players had 


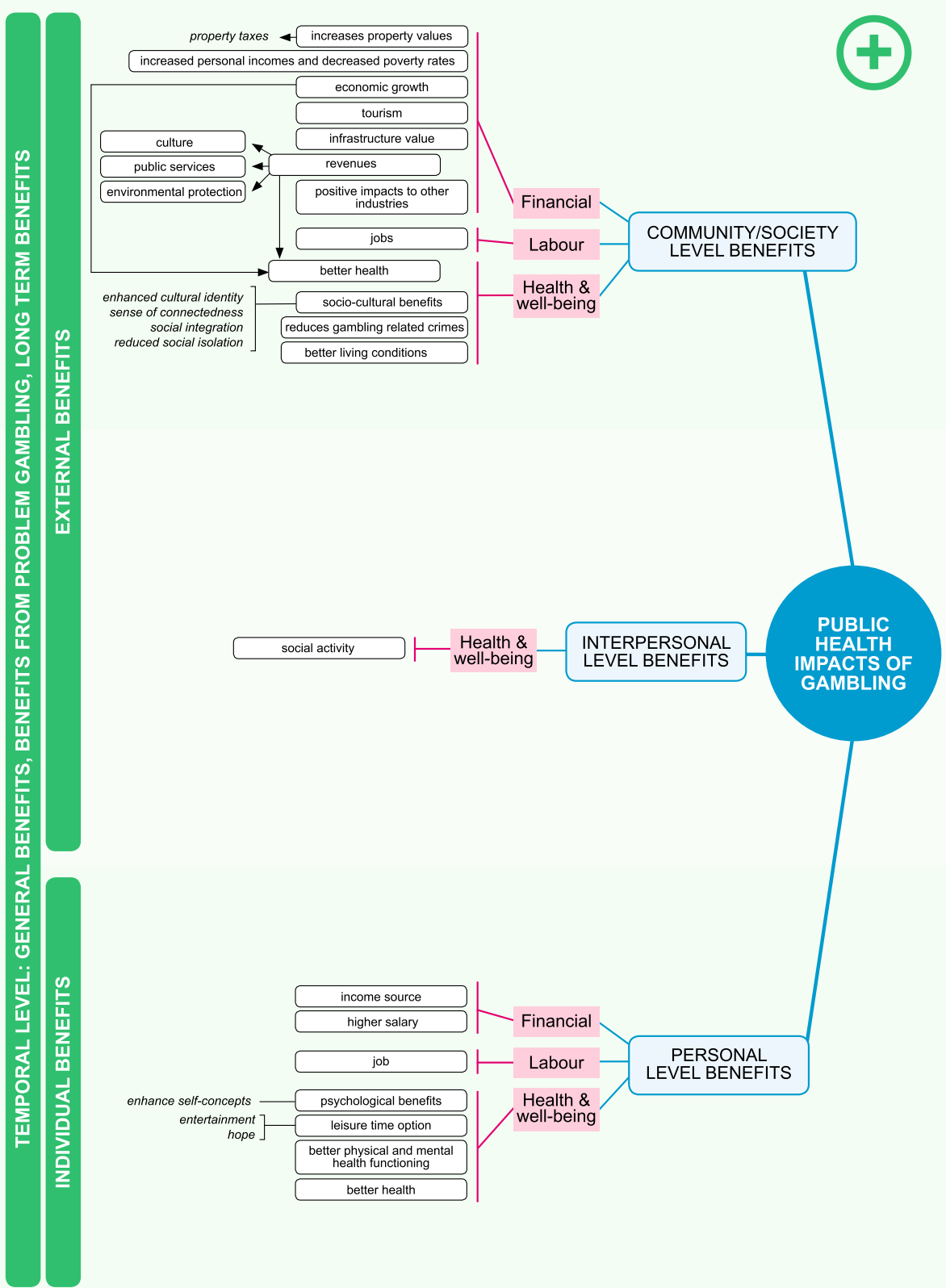

Fig. 2 The positive impacts of gambling on personal, interpersonal and community levels

sold possessions to pay gambling-related debts, compared with $2 \%$ of the "social" players [52]. Among treatmentseeking Finnish gamblers, common financial harm included late payment of bills (66\%) and turning to income support benefits provided by nongovernmental organizations (32\%) [50].

Financial harms have also been observed to be more common in deprived areas [53] and lower socioeconomic groups $[19,54]$. Notably, indigenous people are vulnerable to financial problems $[55,56]$. Financial risks may also be elevated among problem gamblers with psychotic disorders, because one study showed their increased need for financial assistance [24]. However, causality between financial losses and gambling is not always simple. Factors like ill-health may effect both gambling and poverty, and poverty may lead to problematic gambling and vice versa. However, it is clear, that gambling can intensify poverty [57].

Gambling-related debt develops when borrowed money is spent on gambling [58]. Estimations of average current debt per problem gambler have ranged between USD 2500 to greater than USD 53,000 [2, 32, 59, 60]. For problem gamblers, debts are common, because they were three times as likely to report being in debt compared with nongamblers [48]. Among Finnish treatment- 


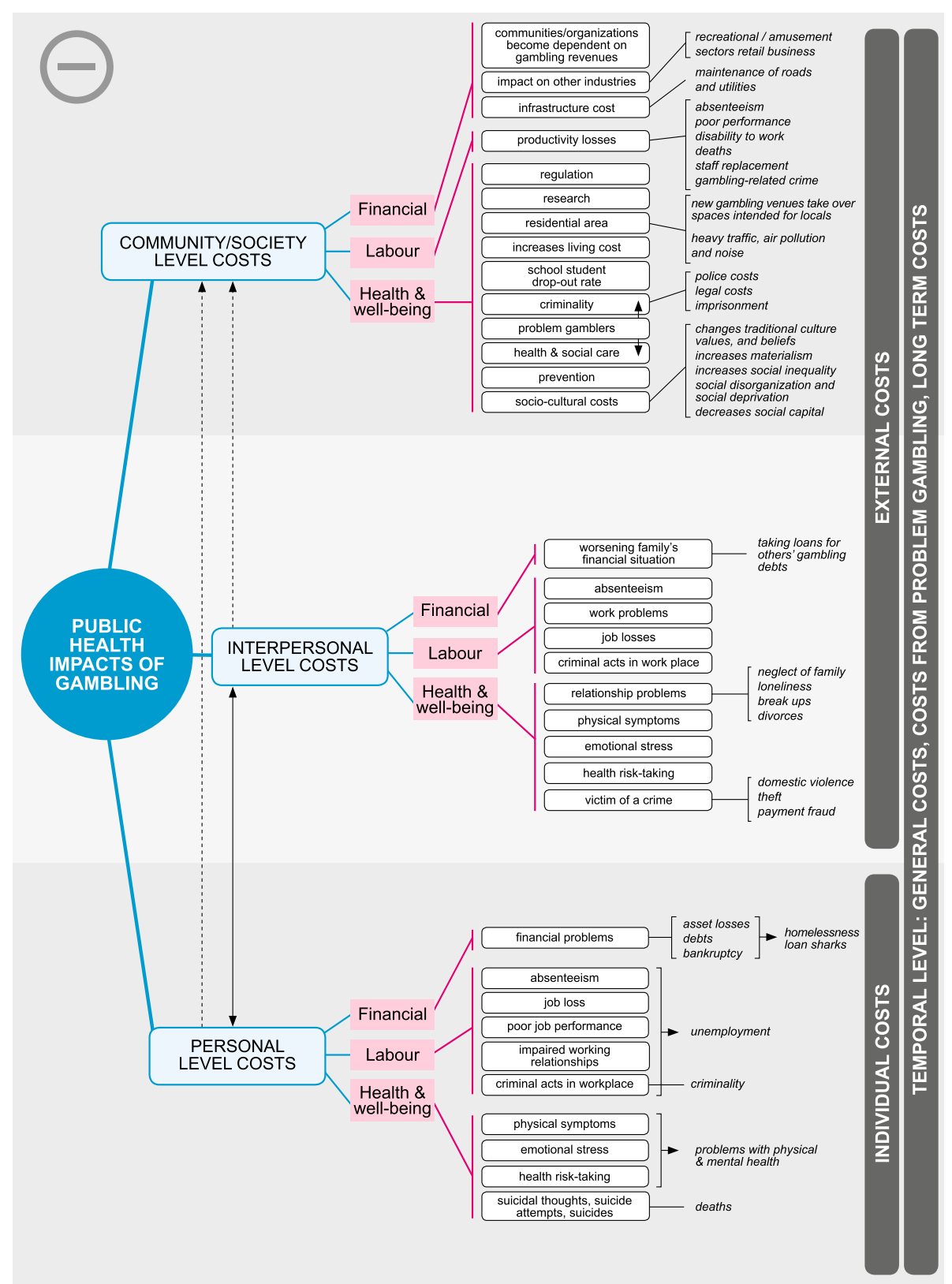

Fig. 3 The negative impacts of gambling on personal, interpersonal and community levels

seeking gamblers, $45 \%$ had debt problems at one time [50]. Further, the more severe the gambling problem the higher the amount of debt [61].

There is also evidence that some games create more debt than others, because treatment-seeking pathological gamblers playing electronic gaming machines had a higher current and lifetime debt than players of scratch tickets and lotteries [62]. Similar results have been found among treatment-seeking male internet gamblers: patients who bet online had higher debt levels compared with offline gamblers [63]. One study observed that $44 \%$ of gamblers regarded as heavy consumers had sometimes taken high- interest instant loans for gambling, and this was more common among female respondents than males [64]. Research has also shown that gambling is a significant contributing factor to indebtedness [65] and often a reason to continue playing [66].

The most serious forms of financial harms because of gambling include bankruptcy and homelessness. These extreme consequences are commonly observed at the point of help-seeking [67]. It is estimated that 10 to $20 \%$ of problem gamblers declare bankruptcy [20, 61, 68]. Gamblers who declared bankruptcy were more likely to have more financial, work-related, marital, and legal problems; 
reported higher rates of depressive and substance use disorders; and were more likely to be daily smokers [68]. Several studies conducted with individuals who are homeless have observed co-occurring problematic gambling [6974]. Studies have estimated that an average of 12 to $39 \%$ of people who are homeless reported having gambling problems [69, 71, 74]. However, similar to other gambling comorbidities, the causal nature of this relationship is difficult to resolve [75]. Gambling may be a risk factor for homelessness: it is often cited as a reason for a lack of housing $[67,75]$, and $82 \%$ of problem gamblers indicated that gambling preceded their homelessness [74].

While the negative financial consequences of gambling are evident, studies have also observed positive financial impacts. For example, in Macao, people working in gambling and related industries earn a higher salary [76], and their nominal wage has increased as a result of casino liberalization [77]. Further, a few studies have shown that for some (especially poker players), although a minority, gambling is a significant income source [78-80].

\section{Labor impacts}

Although studies have observed that gambling often has a positive effect on employment at the community level [81, 82], only a few studies have examined the positive labor impacts at the personal level and all have considered professional poker players, which represent a minority of people and gamblers.

Problem gambling can affect employment in many ways. Gambling during work causes productivity losses, absenteeism, impaired working relationships [50, 83], and termination of employment [84]. It was observed that almost $40 \%$ of problem gamblers reported that gambling had affected their job performance [47], and 61\% reported missing work to gamble [83]. Among Finnish treatment-seeking gamblers, $43 \%$ evaluated that their work performance got worse due to tiredness or distraction, and among those who gambled within the last 12 months, $1 \%$ had used work time to gamble and $0.6 \%$ stated that their work performance had decreased [50]. Almost $60 \%$ of those experiencing problems with gambling were out of paid work for more than one month and approximately $30 \%$ had received some sort of social benefit within the previous year [30]. However, lack of work may not necessarily be because of gambling, although the literature has indicated that problem gamblers were more likely to report poorer work performance. In some cases, problem gambling may lead to criminal acts in the workplace, like embezzlement and stealing goods like office supplies [85].

Employment has critical financial and interpersonal impacts because employment is the primary or major source of household income. Reduced performance in work life can have short- and long-term effects on the life of the individual and their family. Employment also causes effects at the community and societal levels.

\section{Health and well-being impacts}

Notably, self-reported health decreased with the increasing risk of problem gambling: $57 \%$ of nongamblers and $54 \%$ of recreational gamblers reported their general health to be good or excellent, whereas $44 \%$ of low-risk gamblers, $36 \%$ of moderate-risk gamblers, and only $22 \%$ of problem gamblers reported good or excellent general health [30]. However, among gamblers aged 65 years and older, it was observed that past-year gamblers reported more often good or excellent well-being compared with nongamblers [86]. Similarly, another study found that gambling contributed independently and significantly to perceived wellness among older Australians [87]. Among older adults, recreational gambling may offer possibilities for increased socialization, community activity, and travel [10, 88], which may have positive effects on health [89].

The health impacts of gambling are related to significant increases in distress [2]. Emotional or psychological distress can be experiences of guilt, anxiety, helplessness, shame, stigma, grief, and self-hatred [50, 90]. It is estimated that $4-6 \%$ of those who gambled within the last 12 months had experienced feelings of guilt [30, 50]. Among people experiencing high stress or anxiety, physical changes in an individual's biochemistry have been noted [91]. Frequent exposure to stress affects an individual's health outcomes [91], because it has been shown that gambling is associated with heart conditions, high blood pressure, headaches, weight loss, stomach disorders, cardiac arrest, arthritis, indigestion, tachycardia, angina, cirrhosis, and other liver diseases [22, 66, 92]. Notably, problem gamblers were more likely to avoid regular exercise and less likely to seek health care compared with controls [93].

In addition to a lack of regular exercise, problem gamblers had a higher body mass index and were more likely to be classified as obese [93, 94]. They were also more likely to engage in unhealthy lifestyle behaviors, such as watching more than $20 \mathrm{~h}$ of television per week, excessive alcohol consumption, and smoking [93]. Other studies have shown strong associations between gambling and substance use: At-risk and problem gamblers had higher rates of tobacco, alcohol, and drug use [30]. Substance use disorders co-occur commonly with problem gambling, because one study showed 28 and $17 \%$ of gamblers suffer from alcohol and drug use disorders, respectively [23]. By contrast, 15\% of those seeking treatment for alcohol and drug use disorders met the lifetime criteria for problem gambling, and $11 \%$ of the current criteria for problem gambling [95]. Smoking is also common among problematic gamblers [96]. Further, problem gamblers were significantly more likely to have smoked 
more than 100 cigarettes in their lifetime and be current smokers compared with recreational gamblers [30]. Additionally, it has been noticed that among problematic gamblers, 50 to $60 \%$ suffered from nicotine dependence [23, 97].

Many studies have shown that problematic gambling is associated with mental health disorders [23, 24, 88]. In New Zealand, $46 \%$ of problem gamblers had psychological disorders [30]. Among problematic gamblers, almost 38\% had mood disorders and 37\% had anxiety disorders [23]. Additionally, substance use has been shown to co-occur with gambling and mental health problems [43, 97-99]. The causality of these health consequences is not clear because gambling can cause negative health outcomes, but is also a coping mechanism to escape physical, emotional, and substance use problems. However, a longitudinal study observed that at-risk and problem gambling predicted future incidents of major depressive disorder, alcohol dependence, and drug use [100].

The gambling literature has also focused on mortality because of suicide [101, 102]. Notably, problematic gamblers have higher rates of suicidal thoughts, suicide attempts, and completed suicides [103-106]. In Finland, $5 \%$ of treatment-seeking problem gamblers had attempted suicide, whereas it was $0.1 \%$ among the population sample [50]. Studies have also shown a positive correlation among suicidal ideation, suicide attempts, and gambling severity $[103,107,108]$. Heightened risk for gambling-related suicidality is found among youth experiencing gambling problems $[109,110]$. A link between gambling and suicide may be explained by excessive debts and escalation of family, legal, and mental and substance-related problems $[20,108]$. Notably, the interaction between suicide and gambling is complex, and it would be an oversimplification to assert that gambling causes suicides [17].

The literature also demonstrates the positive effects of gambling. Especially among older adults, recreational gamblers reported better physical and mental health functioning than did older nongamblers [94]. Further, it was proposed that the psychological benefits of gambling may reinforce and enhance seniors' self-concepts [6]. Additionally, it was stated that among lower socioeconomic groups, gaining pleasure from the hope of a small win and the possibility of making a choice on the use of scarce resources may be important in helping maintain optimism in the face of difficult life circumstances [111]. One of the most obvious positive impacts of gambling is its entertainment value and usefulness as an additional leisure option [112]. Although most adults have engaged in gambling activities, only a minority report that gambling is a very important leisure activity for them or that it has replaced other leisure activities [113].

\section{Interpersonal level impacts Financial impacts}

Gambling affects more people than just the gambler, because an estimate indicates that one person's gambling problem typically affects 5 to 10 people [2]. Thus, the percentage of people whose lives are negatively impacted by problem gambling may be 3 or 4 times as high than the problem gambling prevalence in the general population $[114,115]$. In New Zealand, approximately $30 \%$ of adults said they knew at least one person who has/had a problem with gambling, and approximately $8 \%$ experienced that someone else's gambling had affected them personally [30]. Partners and children who share finances with a gambler often experience greater levels of harm [116]. Most commonly reported harms by partners were financial impacts, like increased debt and financial strain [29, 117]. Financial problems can also cause partners to go without daily household items and quality food, cause problems with payments and loss of utilities [118], and further cause the inability to afford medication or treatment [119]. Additionally, partners commonly take loans for someone else's gambling debts [120]. Children can experience deprivation of essential items and insecurity of material needs $[121,122]$.

\section{Labor impacts}

In Australia, $84 \%$ of the concerned significant others (CSOs) of people with problem gambling reported that their partners' gambling had negative impacts on their own employment. Participants with an Asian cultural background had significantly higher employment impacts than their non-Asian counterparts. This was the case also for participants with prior counseling experience [116]. In Sweden, female CSOs reported more sick leave days and months of absence from work because of illness, and male CSOs reported more fear of losing employment and work problems [120].

\section{Health and well-being impacts}

Financial difficulties can lead to relationship problems, which is common. CSOs experienced a great deal of relationship distress [123], and 96\% reported that gambling had negative impacts on their relationships [116]. Among problem gamblers, separation and divorce were more common [25, 115, 124]. In Finland, among the population sample, only $0.1 \%$ had experienced separation or ending a relationship because of gambling, whereas among treatment-seeking problem gamblers the it was $10 \%$ [50]. Conflict, loss of trust due to dishonesty, concealment of the gambling problem, and need to take responsibility for family and household matters can drive couples to separation or divorce [117].

It is not uncommon that significant others end up as victims of a crime [18]. Petty theft from family members 
and illicit lending are relative common forms of interpersonal harm. Violence associated with gambling is an extreme form of interpersonal harm. It was observed that pathological gambling increased the odds of perpetrating dating violence, severe marital violence, and severe child abuse even when adjusted for mental disorders [125]. Pathological gambling has also been observed to be associated with homicide in the family $[105,126]$. Additionally, among problem gamblers, $63 \%$ had been victims or perpetrated intimate partner violence (IPV) [127]. Further, 38\% of problem gamblers had experienced physical IPV, and $37 \%$ were perpetrators of physical IPV [128]. Additionally, in Asian countries and Asian communities living abroad, high rates of problem gambling and family violence have been observed [129, 130]. Among help-seeking CSOs, $20 \%$ were victims of violence, $11 \%$ were perpetrators, and $26 \%$ were both victims and perpetrators [131]. In Finland $2 \%$ of suspected gambling related crimes were intimate partnership violence resulted from gambling problems [132]. This, however, constitute only a small amount of the total partnership violence.

Experiencing isolation and self-blame is common among significant others. Some spouses attempt to conceal partners' gambling [117]. They felt that the gamblers did not spend sufficient time with them, and they had withdrawn from social life due to their inability to pay for social activities [118]. Thus, CSOs commonly experience isolation and loneliness [120, 133]. Self-blame is another identified pervasive harm, and spouses often feel that they should have been able to prevent their partner from gambling [117].

Gambling is also linked to increased possibilities for social actions [6,7]. Seniors highlighted the social aspects of their casino visits: they liked having a place to meet and socialize with others [134]. Gambling is also common pastime activity among families [135]; however, this is not necessarily a positive thing because the majority of young people are introduced to gambling by their parents [136].

CSOs experienced poorer physical and mental health than the general population [120,133, 137]. Symptoms of depression and emotional distress and feelings of melancholy were common $[116,120]$ as were physical symptoms, like headaches, insomnia, high blood pressure, panic attacks, and feelings of tiredness or exhaustion [138]. CSOs also had problems with their own gambling behavior [139] and with other addictions [120,137], like risky alcohol consumption for males and daily smoking for females [133].

Children of problem gamblers have an elevated risk of gambling problems [140]. Further, health risk behaviors, such as smoking tobacco, drinking alcohol, and drug abuse are common [141]. These children also have higher a risk for physical and mental health problems and suicide attempts [122, 142, 143]. The effects of parental gambling on children's overall well-being can be significant, and children can suffer long-term effects because of neglect and uninvolved parenting [121]. Additionally, children whose parents are employed by casinos can suffer from neglect because they are often left at home without much care and can lose contact with their parents [76].

\section{Community/society level impacts \\ Financial impacts}

The introduction of gambling has been associated with increased government revenue and overall economic growth [76, 77, 113, 144]. Governments earn revenue from gambling through several means: the taxation of gambling venues and operations, becoming directly involved in the provision of gambling and receiving its revenue, or by government controlled monopolies, which can deliver various forms of gambling and taxation of gambling winnings [32]. Other studies have observed that gambling does not impact government revenue, and in some cases the impacts have been negative $[145,146]$. When new forms of gambling have significant negative impacts on other forms of gambling and states continue to benefit from revenues from the new forms, the net revenues may not change. These revenues can be used for public services, but also to avoid raising taxes and reduce government debt [147].

Some forms of gambling are provided by charitable and community organizations, and these profits are used for their own operation, or the governments' gambling revenues are earmarked for these groups [32]. However, this scenario can make communities and organizations dependent on gambling revenues [148]. Gambling can also have negative impacts on public services, for example, new forms of gambling in the community can negatively affect charitable gambling revenue through direct competition [149].

Another positive impact of gambling has been increased personal incomes and decreased poverty rates [81, 150, 151]. This was especially observed in Native American communities in the United States [81, 150]. Casino development has also led to an increase in entertainment and recreation facilities, restaurants, shopping places, and bars as well as public performances and exhibitions [151].

The construction of a new gambling venues can increase the physical assets and wealth of a local community $[113,152]$, especially when infrastructure improvements and construction of complementary businesses (e.g., hotels, restaurants) occur [32, 76, 151]. Notably, increased infrastructural value is not associated with all types of gambling but primarily with those that involve the construction of new venues like casinos [152,153]. The introduction of machine gaming to Queensland clubs and hotels increased infrastructure value when clubs constructed new building projects and facility improvements 
[154]. These infrastructure improvements also attract a large number of tourists [151].

Who finances these new gambling venues is important whether these investments can be viewed as cost or benefits; when financed partly or wholly by governments rather than by private developers, investment is construed as more of a "cost," although the wealth of the local community increases [32]. The costs of public transportation and the required police and fire protection are borne by governments, and the maintenance of roads, electricity, and water supply are usually a government responsibility too $[155,156]$.

Gambling can also impact other industries. Positive impacts have been observed especially in communities where casinos are located in tourist areas offering other entertainment and sightseeing opportunities and where the casinos' clients are outside the immediate area and require overnight stays [76, 157-159]. The most common business sectors that benefit from gambling are hotels, restaurants, and other types of entertainment [160, 161]. In addition to the community level, gambling introduction has been shown to increase overall business revenue on a state-wide level [146, 162]. However, some studies have not demonstrated that gambling has significant impacts (either positive or negative) on other industries [113, 163]. Notably, negative impacts as a result of gambling introduction have been reported in the recreational/amusement sectors [164] and for retail businesses [165]. Small ventures are especially likely to have problems with hiring and retaining staff due to the casino expansion, inflation, and increases in shop rents and operating costs $[76,151]$.

\section{Labor impacts}

The introduction of a new form of gambling often has positive effects on employment [81, 82]. Gambling that attracts visitors and brings money to a community has potential positive benefits for other business sectors and further employment $[76,166]$. This phenomenon is particularly true for the hospitality industry [155]. Employment growth in different types of jobs has helped Macao diversify its economy toward healthier economic development, and foreign investments in casinos have upgraded the city's international status [76]. Additionally, employment gains were reported for casinos [82]. Automated forms of gambling like electronic gaming machines have only minor impacts on employment [32]. Further, most gambling industry employment is low skilled and low paid; however, a large majority of new gambling employees tend to come from similar low-skilled and lowwage sectors [32, 113]. In Macao, many sectors have reported difficulties recruiting and maintaining staff because people are eager to work for the casino hotels to earn a higher salary [76]. When staff comes from outside the local area, the employment benefits of gambling to a local area can be minimal [32]. In Macao, the government and casino operators chose to import migrant workers to employ a sufficiently skilled workforce [77]. Further, when a situation is examined on a larger than local scope, employment gains of gambling have been minimal or nonexistent $[2,167]$.

Studies have also found work-related costs because of problem gambling. It is estimated that community cost due to productivity losses varies between US\$ 6 million to $\$ 39$ million [168]. A study conducted in Victoria Australia estimated that productivity loss in the workplace was $\$ 323$ million [42]. The total cost to the employer of gambling-related staff replacement was $\$ 34.6$ million, and the unemployment benefit payments $\$ 10.8$ million. Absenteeism due to gambling problems cost Victoria an estimated \$46 million, and the total cost of gambling-related crime was in 2014-15 \$22.5 million. The total cost of fatality by suicide due to gambling problems was estimated to be $\$ 28.6$ million [42].

\section{Health and well-being impacts}

Governments are typically responsible for regulating gambling operations. Regulations and administration procedures are required to secure functions of the industry and maintain social stability [46]. Thus, increased gambling supply comes with increased regulation costs [168]. In a society where gambling is legal, anyone could suffer from gambling harms. Thus, resources are required to prevent this phenomenon from occurring. A certain amount of public resources also must be allocated to gambling-related professional training and research [46]. One of the major costs of gambling problems borne by governments is the funding for gambling regulations, research, and treatment services, and it is estimated that in 2014-15 the Victorian Government spent at least $\$ 52$ million on these services [42].

Government revenues are also used to improve public services (e.g., health, education, culture, social security) $[152,153,169]$. In Macao, as a result of casino introduction, more social welfare and benefits have been given to the local people. Additionally, the free education period was prolonged and free medical care and bus transportation for those above 65 years old was offered [76]. Further, public expenditures on environmental protection increased [151]. Additionally, in North American Aboriginal communities, improvements in living conditions and public health have occurred [150, 158]. Enhanced cultural identity has also been reported after casino openings [158]. However, some studies have highlighted how gambling changes traditional Aboriginal culture, values, and beliefs [170, 171], and increasing materialism has also raised some concerns [76, 171]. In Macao, earning money from the casino business was regarded as easier and faster than having a higher education. This phenomenon diminished interest of young 
people in studying and increased the school drop-out rate [76].

Gambling brings social problems and leads to increased demand for social services [76]. Studies have shown that increased availability of gambling is associated with increased problem gambling rates $[155,172]$. A positive relationship has even been observed between casino proximity and problem gambling [173]. Increased gambling opportunities are also associated with increases in social inequality. Higher-income households spend on average much more on gambling, but poorer households lose a higher proportion of their income on gambling [174, 175]. In Germany, the lowest income quintile spent an average of $12 \%$ of their net income on gambling, compared with only $2 \%$ in the highest quintile. Overall, $50 \%$ of gambling turnover was borne by $12.6 \%$ of all gamblers [176]. In Finland 50\% of gambling turnover come from just 5\% of all gamblers [177].

Gambling can have negative effects on quality of life: the introduction of new casinos has increased traffic and cause noise and pollution [76, 149, 151]. Further, casinos can take over areas originally designed for residential and public facilities and conquer green and leisure spaces intended for locals [76]. One study found that quality of life change from gambling is either very modest or negative [178]. Gambling can also increase criminality in several ways [32]. Firstly, by increasing the number of problem gamblers, because problem gamblers are more likely to commit crimes than the general population [110, 179]. Secondly, increasing opportunities for illegal activity and creating venues that sell alcohol and potentially affect alcohol-related offences [32]. The introduction of casinos has been associated with increased violent crime [180] and rates of driving while intoxicated [181]. And thirdly, by increasing the overall number of visitors to the area, because increases in population and tourism contribute to increased crime rates [182]. It is estimated that pathological and problem gambling accounts for $\$ 1000$ in excess lifetime police costs per person [2]. Study conducted in Sweden proposed that the total court costs for criminal cases caused by gambling would be approximately between $\$ 3$ and $\$ 72$ per problem gambler [183]. Cost to the prison system associated with people who are problem gamblers was estimated to be between $\$ 51$ and $\$ 243$ million per year [184]. Notably, gambling can decrease the rate of illegal gambling [113].

Property and other living prices have increased faster than average salaries as a result of casino gambling [76]. Further, some studies have shown declines in social capital because of casino introduction [27] and increases in social disorganization and social deprivation [185]. Additionally, the negative consequences of gambling have been linked with social integration, a sense of connectedness, and reduced social isolation [186, 187]. Gambling is also seen as a community activity that brings people together [188].

\section{Conclusions}

The conceptual model developed in this article offers a base on which to start building common methodology for assessing the impact of gambling on the society - a target explicated by, e.g. Walker [37] and Williams and others [32]. In the discussion about the best methodological and theoretical approaches for analyzing the impacts of gambling, the main issue is how to measure the social impacts. Most of the social impacts are nonmonetary by nature and are often difficult to measure and thus ignored in calculations. Similarly, personal and interpersonal impacts have often been excluded from calculation, largely for the same reason as social impacts. Except for the most obvious positive impact of gambling, namely, gambling revenues for communities, studies have often concentrated on the negative side of gambling impacts. The central focus has been on problem gambling; thus, many gambling harms have been ignored although gambling-related harms also occur among those who are not problem gamblers and nongamblers within harms reach, such as significant others and the wider community. These methodological deficiencies are common in the gambling impacts literature and cause a significant bias in current knowledge.

As mentioned earlier, gambling causes external impacts that affect more people than just the gambler. Financial, labor, and health and well-being impacts have been observed at the individual, interpersonal, and community/society levels. For example, gamblers' increased debt and financial strain affect family members' lives, and the effects of escalating into bankruptcy and homelessness are also observed in the community. Thus, it is of utmost importance that impacts are examined on separate levels. Additionally, these impacts can have longterm effects and create a change in the life course of an individual, and even pass between generations. Key methodological challenges relate to what portion of impacts are the effects of gambling and how these should be measured. We faced similar methodological challenges when examining the interpersonal and community/society level impacts. Community/society level impacts that are nonmonetary, such as quality of life, social cohesion, and other attributes of social capital, have had less emphasis in studies. These studies have been primarily conducted in North America, and the majority of analyses concerns casino impacts.

Although the PHIGam model attempts to be as universal as possible, it is important to note the context in which gambling takes place is critical when examining gambling impacts. Opening a casino in an area where gambling opportunities have been limited has a greater impact than in area where gambling has been widely available. In the "adaptation hypothesis" $[189,190]$, it is argued that the negative effects of gambling are higher 
when gambling or new games are newly introduced in community but tend to diminish over time. However, a more recent study has shown that overall rates of harm stabilized when participation continued to fall and for some groups participation reduced but harms increased [191]. Thus, it is suggested that "adaptation hypothesis" over-simplifies the situation [191, 192]. Financial harms of gambling have been shown to be more common among deprived areas, whereas in Macao, the nominal wages of people working in gambling and related industries has increased because of casino liberalization. Additionally, the type of gambling presented affects impacts because it was shown that some games create more debt than others. Finally, it is important to understand how revenues are derived and disbursed.

The debate leading to the formation of the model on Public Health Impacts of Gambling utilized existing theoretical and empirical literature to form a structure that can be used to locate individual pieces of research. As shown in the Figures, empirical work has largely concentrated on the costs of gambling, especially costs on the community level. The Figures can be used to identify areas where research is scarce: for example, no research was found analyzing financial or labor benefits to the significant others of gamblers. Filling the gaps in knowledge is essential in forming a balanced evidence base on the impacts of gambling. Ideally, this evidence could be the starting point in formulating public policies on gambling.

\section{Abbreviations \\ CBA: Cost-benefit analysis; CSO: Concerned significant other; DW: Disability weight; HRQL: Health-related quality of life; IPV: Intimate partner violence; PHIGam: Public Health Impacts of Gambling; SEIG: Socioeconomic impact of gambling}

\section{Declarations}

The authors wish to acknowledge the contribution of the reviewers who introduced the idea of integrating the Temporal level into the Model.

\section{Authors' contributions}

All authors TLa, TLi, AKo made substantial contributions to the conception and design of the study. TLa drafted the first version of the manuscript and TLi and AKo were involved in critical revision for important intellectual content. All authors read and approved the final manuscript.

\section{Funding}

The study was financially supported by the Ministry of Social Affairs and Health, Helsinki, Finland (the 52 Appropriation of the Lotteries Act). The funder had no further role in the writing the article or in the decision to submit it for publication.

\section{Availability of data and materials}

Not applicable.

\section{Ethics approval and consent to participate}

Not applicable.

\section{Consent for publication}

Not applicable.

\section{Competing interests}

The authors declare that they have no competing interests.

\section{Author details}

${ }^{1}$ Finnish Foundation for Alcohol Studies, P.O. Box 30, Fl-00271 Helsinki, Finland. ${ }^{2}$ Faculty of Social Sciences, Health Sciences, Tampere University, Fl-33014 Tampere, Finland.

Received: 4 October 2018 Accepted: 26 July 2019

Published online: 09 August 2019

\section{References}

1. Derevensky JL. Teen gambling: understanding a growing epidemic. New York: Rowman \& Littlefield Publishing; 2012.

2. Productivity Commission 2010, Gambling, Report no. 50, Canberra. Available from: Available from: https:/www.pc.gov.au/inquiries/completed/ gambling-2010/report.

3. Griffiths MD. Problem gambling in Europe: what do we know? Casino Gaming Int. 2010;6(2):81-4.

4. Martin F, Lichtenberg PA, Templin TN. A longitudinal study: casino gambling attitudes, motivations, and gambling patterns among urban elders. J Gambl Stud. 2011;27(2):287-97.

5. McNeilly DP, Burke WJ. Late life gambling: the attitudes and behaviors of older adults. J Gambl Stud. 2000;16(4):393-415.

6. Loroz PS. Golden-age gambling: psychological benefits and self-concept dynamics in aging consumers' consumption experiences. Psychol Mark. 2004;21(5):323-49.

7. Lee C-K, Lee Y-K, Bernhard BJ, Yoon Y-S. Segmenting casino gamblers by motivation: a cluster analysis of Korean gamblers. Tour Manag. 2006;27(5): $856-66$

8. Lee C-K, Bernhard BJ, Kim J, Fong T, Lee TK. Differential gambling motivations and recreational activity preferences among casino gamblers. J Gambl Stud. 2014;31(4):1833-47.

9. Nower L, Blaszczynski A. Gambling motivations, money-limiting strategies, and precommitment preferences of problem versus non-problem gamblers. J Gambl Stud. 2010;26(3):361-72.

10. Korn D, Shaffer H. Gambling and the health of the public: adopting a public health perspective. J Gambl Stud. 1999;15(4):289-365.

11. Potenza MN. Review. The neurobiology of pathological gambling and drug addiction: an overview and new findings. Philos Trans R Soc Lond Ser B Biol Sci. 2008;363(1507):3181-9

12. Wong ILK, So EMT. Internet gambling among high school students in Hong Kong. J Gambl Stud. 2014;30(3):565-76.

13. World Health Organization. The ICD-10 classification of mental and behavioural disorders: clinical descriptions and diagnostic guidelines. Geneva: World Health Organization; 1992.

14. American Psychiatric Association. Diagnostic and statistical manual of mental disorders (5th ed.). Washington, DC: American Psychiatric Association; 2013

15. Williams RJ, Volberg RA, Stevens RMG. The population prevalence of problem gambling: Methodological influences, standardized rates, jurisdictional differences, and worldwide trends. nd. Alberta: the Ontario Ministry of Health and Long Term Care; 2012.

16. Bühringer G, Braun B, Kräplin A, Neumann M, Sleczka P. Gambling: Two sides of the same coin. AR Policy Brief. 2013;2:5.

17. Browne M, Bellringer M, Greer N, Kolandai-Matchett K, Rawat V, Langham E, Rockloff $M$, et al. Measuring the burden of gambling harm in New Zealand. Ministry of Health: Wellington; 2017.

18. Langham E, Thorne H, Browne M, Donaldson P, Rose J, Rockloff M. Understanding gambling related harm: a proposed definition, conceptual framework, and taxonomy of harms. BMC Public Health. 2016;16(1):80.

19. Castrén S, Basnet S, Pankakoski M, Ronkainen J-E, Helakorpi S, Uutela A, et al. An analysis of problem gambling among the Finnish working-age population: a population survey. BMC Public Health. 2013;13(1):519.

20. Komoto Y. Factors associated with suicide and bankruptcy in Japanese pathological gamblers. Int J Ment Heal Addict. 2014;12(5):600-6.

21. Santangelo G, Barone P, Trojano L, Vitale C. Pathological gambling in Parkinson's disease. A comprehensive review. Parkinsonism Relat Disord. 2013;19(7):645-53.

22. Morasco BJ, Pietrzak RH, Blanco C, Grant BF, Hasin D, Petry NM. Health problems and medical utilization associated with gambling disorders: results from the national epidemiologic survey on alcohol and related conditions. Psychosom Med. 2006;68(6):976-84. 
23. Lorains FK, Cowlishaw S, Thomas SA. Prevalence of comorbid disorders in problem and pathological gambling: systematic review and meta-analysis of population surveys. Addiction. 2011;106(3):490-8.

24. Haydock M, Cowlishaw S, Harvey C, Castle D. Prevalence and correlates of problem gambling in people with psychotic disorders. Compr Psychiatry. 2015:58:122-9.

25. Mathews M, Volberg R. Impact of problem gambling on financial, emotional and social well-being of Singaporean families. Int Gambl Stud. 2013;13(1): $127-40$.

26. Gonzales AA. Gaming and displacement: winners and losers in American Indian casino development. Int Soc Sci J. Blackwell Publishing. 2003;55(175):123-33.

27. Griswold MT, Nichols MW. Social Capital and Casino Gambling in U.S. Communities. Soc Indic Res. Kluwer Academic Publishers. 2006;77(3):369-94

28. Li E, Browne M, Rawat V, Langham E, Rockloff M. Breaking bad: comparing gambling harms among gamblers and affected others. J Gambl Stud. 2017; 33(1):223-48.

29. Shannon K, Anjoul F, Blaszczynski A. Mapping the proportional distribution of gambling-related harms in a clinical and community sample. Int Gambl Stud. 2017;17(3):366-85.

30. Abbott M, Bellringer M, Garrett N, Mundy-McPherson S. New Zealand 2012 national gambling study: gambling harm and problem gambling. Auckland: Auckland University of Technology; 2014.

31. Wardle H, Moody A, Spence S, Orford J, Volberg R, Jotangia D, et al. British gambling prevalence survey 2010. London: Stationery Office; 2010.

32. Williams R, Rehm J, Stevens R. The social and economic impacts of gambling. Final Report prepared for the Canadian Consortium for Gambling Research; 2011.

33. Abbott M, Binde P, Hodgins D, Pereira A, Volberg R, Williams RJ. Conceptual framework of harmful gambling: An international collaboration. Guelph: Ontario Problem Gambling Research Centre (OPCRC); 2013.

34. Abbott M, Binde P, Clark L, Hodgins D, Korn D, Pereira A, et al. Conceptual framework of harmful gambling: an international collaboration revised edition. 2015

35. Abbott M, Binde P, Clark L, Hodgins D, Johnson Mark, Manitowabi Darrel, Quilty L, Spångberg Jessika, Volberg R, et al. Conceptual Framework of Harmful Gambling: An International Collaboration. 2018.

36. Moeller $L$, Matic $S$. Best practice in estimating the costs of alcohol recommendations for future studies. Best practice in estimating the costs of alcohol : recommendations for future studies. Copenhagen: WHO Regional Office for Europe; 2010.

37. Walker DM. Problems in quantifying the social costs and benefits of gambling. Am J Econ Sociol. 2007;66(3):609-45.

38. Grinols EL. Gambling in America : costs and benefits. Cambridge: Cambridge University Press; 2004.

39. Anielski M, Braaten A. The socio-economic impact of gambling (SEIG) framework: an assessment framework for Canada: in search of the gold standard. Edmonton: Anielski Management; 2008.

40. Walker DM, Barnett AH. The social costs of gambling: an economic perspective. J Gambl Stud. 1999;15(3):181-212.

41. Browne M, Goodwin BC, Rockloff MJ. Validation of the short gambling harm screen (SGHS): a tool for assessment of harms from gambling. J Gambl Stud. 2017;34(2):499-512.

42. Browne M, Greer N, Armstrong T, Doran C, Kinchin I, Langham E, et al. The social cost of gambling to Victoria. Melbourne: Victorian Responsible Gambling Foundation; 2017.

43. Rodriguez-Monguio R, Brand E, Volberg R. The economic burden of pathological gambling and co-occurring mental health and substance use disorders. J Addict Med. 2017;24:1.

44. Browne M, Greer N, Rawat V, Rockloff M. A population-level metric for gambling-related harm. Int Gambl Stud. Routledge. 2017;31:1-14.

45. Browne M, Rawat V, Greer N, Langham E, Rockloff M, Hanley C. What is the harm? Applying a public health methodology to measure the impact of gambling problems and harm on quality of life. J Gambl Issues. 2017;0(36): 28-50.

46. Fong DKC, Fong HN, Li SZ. The social cost of gambling in Macao: before and after the liberalisation of the gaming industry. Int Gambl Stud. 2011; 11(1):43-56

47. Queenlands Goverment. Queensland household gambling survey report 2011-12. 2012.

48. Wardle H, Seabury C, Ahmed H, Payne C, Byron C, Corbett J, et al. Gambling behaviour in England and Scotland. Findings from the health survey for
England 2012 and Scottish health survey 2012. Prepared fornThe Gambling Commission; 2014.

49. Salonen A, Latvala T, Castrén S, Selin J, Hellman M. Rahapelikysely 2016 : Rahapelaaminen, rahapelihaitat ja rahapelien markkinointiin liittyvät mielipiteet Uudellamaalla, Pirkanmaalla ja Kymenlaaksossa. [Gambling harms survey 2016. Gambling, gambling-related harm and opinions on gambling marketing in Uusim]. Helsinki: National Institute for Health and Welfare (THL). Report 9/2017; 2017.

50. Salonen AH, Hellman M, Latvala T, Castrén S. Gambling participation, gambling habits, gambling-related harm, and opinions on gambling advertising in Finland in 2016. Nordic Stud Alcohol Drugs. 2018;35(3):215-34.

51. Salonen A, Castrén S, Latvala T, Heiskanen M, Alho H. Rahapelikysely 2016 Rahapelaaminen, rahapelihaitat jarahapelien markkinointiin liittyvät mielipiteet rahapeliongelmaan apua hakevien Peliklinikan asiakkaiden näkökulmasta. [Gambling Harms Survey 2016. Gambling, gambling-related harm and opinions on gamb]. Helsinki: National Institute for Health and Welfare (THL). Report 8/2017; 2017.

52. Fisher S. Gambling and problem gambling among casino patronss', report to a consortium of the British casino industry; 1996.

53. Tu D, Gray RJ, Walton DK. Household experience of gambling-related harm by socio-economic deprivation in New Zealand: increases in inequality between 2008 and 2012. Int Gambl Stud. 2014;14(2):330-44.

54. Walker SE, Abbott MW, Gray RJ. Knowledge, views and experiences of gambling and gambling-related harms in different ethnic and socioeconomic groups in New Zealand. Aust N Z J Public Health. 2012;36(2): $153-9$.

55. Hing N, Breen H, Buultjens J, Gordon A. A profile of gambling behaviour and impacts among indigenous Australians attending a cultural event in New South Wales. Aust Aborig Stud. 2012;2:3-20.

56. Breen HM, Hing N, Gordon A. Indigenous gambling motivations, behaviour and consequences in northern New South Wales, Australia. Int J Ment Heal Addict. 2011;9(6):723-39.

57. Barnard M, Kerr J, Kinsella R, Orford J, Reith G, Wardle H. Exploring the relationship between gambling, debt and financial management in Britain. Int Gambl Stud. 2014;14(1):82-95.

58. Downs C, Woolrych R. Gambling and debt: the hidden impacts on family and work life. Community Work Fam. 2010;13(3):311-28.

59. Breen RB. Rapid onset of pathological gambling in machine gamblers: a replication. Int J Ment Heal Addict. 2004;2:44-9.

60. Breen RB, Zimmerman M. Rapid onset of pathological gambling in machine gamblers. J Gambl Stud. 2002;18(1):31-43.

61. Gerstein D, Hoffman J, Larison C, Engelman L, Murphy S, Palmer A, et al. Gambling impact and behavior study: report to the national gambling impact study commission. Chicago: National Opinion Research Center at the University of Chicago; 1999.

62. Petry NM. A comparison of treatment-seeking pathological gamblers based on preferred gambling activity. Addiction. 2003;98(5):645-55.

63. Estévez A, Rodríguez R, Díaz N, Granero R, Mestre-Bach G, Steward T, et al. How do online sports gambling disorder patients compare with land-based patients? J Behav Addict. 2017;6(4):639-47.

64. Lähteenmaa J, Strand T. Pelin jälkeen: velkaa vai voittoja? : tutkimus velan ottamisesta rahapeleihin, erityistarkastelussa nettipokeri ja pikavippaaminen [After gambling: in the red or in the black? A study of gambling on credit, with a focus on online poker and instant loans]. Helsinki: STAKES, Reports 25/2008; 2008.

65. Yip PSF, Yang KCT, Ip BYT, Law YW, Watson R. Financial debt and suicide in Hong Kong SAR. J Appl Soc Psychol. 2007;37(12):2788-99.

66. Chun J, Cho S, Chung I-J, Kim S. Economic and psychosocial impact of problem gambling in South Korea. Asian J Gambl Issues Public Health. 2011; 2(1):29-38.

67. Carroll A, Davidson T, Marsh D, Rodgers B. Help-seeking and uptake of services amongst people with gambling problems in the ACT. Centre for Gambling Research; 2011.

68. Grant JE, Schreiber L, Odlaug BL, Kim SW. Pathologic gambling and bankruptcy. Compr Psychiatry. 2010;51(2):115-20.

69. Sharman S, Dreyer J, Aitken M, Clark L, Bowden-Jones H. Rates of problematic gambling in a British homeless sample: a preliminary study. J Gambl Stud. 2015:31(2):525-32.

70. Matheson Fl, Devotta K, Wendaferew A, Pedersen C. Prevalence of gambling problems among the clients of a Toronto homeless shelter. J Gambl Stud. 2014;30(2):537-46 
71. Crane M, Byrne K, Fu R, Lipmann B, Mirabelli F, Rota-Bartelink A, et al. The causes of homelessness in later life: findings from a 3-nation study. J Gerontol B Psychol Sci Soc Sci. 2005;60(3):S152-9.

72. Harris T, Kintzle S, Wenzel S, Castro CA. Expanding the understanding of risk behavior associated with homelessness among veterans. Mil Med. 2017; 182(9):e1900-7.

73. Hamilton-Wright S, Woodhall-Melnik J, Guilcher S, Schuler A, Wendaferew A, Hwang S, et al. Gambling in the landscape of adversity in youth: reflections from men who live with poverty and homelessness. Int J Environ Res Public Health. 2016;13(9):854.

74. Sharman S, Dreyer J, Clark L, Bowden-Jones H. Down and out in London: addictive behaviors in homelessness. J Behav Addict. 2016;5(2):318-24.

75. Holdsworth L, Tiyce M. Untangling the complex needs of people experiencing gambling problems and homelessness. Int J Ment Heal Addict. 2013;11(2):186-98

76. Wan YKP. The social, economic and environmental impacts of casino gaming in Macao: the community leader perspective. J Sustain Tour. 2012; 20(5):737-55.

77. Zheng V, Hung EPW. Evaluating the economic impact of casino liberalization in Macao. J Gambl Stud. 2012;28(3):541-59.

78. Bjerg O. Problem gambling in poker: money, rationality and control in a skill-based social game. Int Gambl Stud. 2010;10(3):239-54.

79. McCormack A, Griffiths MD. What differentiates professional poker players from recreational poker players? A qualitative interview study. Int J Ment Heal Addict. 2012;10(2):243-57.

80. Weinstock J, Massura CE, Petry NM. Professional and pathological gamblers: similarities and differences. J Gambl Stud. 2013;29(2):205-16.

81. Gonzales AA, Lyson TA, Mauer KW. What does a casino mean to a tribe? assessing the impact of casino development on Indian reservations in Arizona and New Mexico. Soc Sci J. 2007:44(3):405-19.

82. Wenz M. Matching estimation, casino gambling and the quality of life. Ann Reg Sci. 2008;42(1):235-49.

83. Griffiths M. Internet gambling in the workplace. J Work Learn. 2009;21(8):658-70.

84. Eby LT, Mitchell ME, Gray CJ, Provolt L, Lorys A, Fortune E, et al. Gamblingrelated problems across life domains: an exploratory study of non-treatmentseeking weekly gamblers. Community Work Fam. 2016;19(5):604-20.

85. Downs C, Woolrych R. Gambling and debt path finder study. Manchester: Research Institute Health and Social Change Occasional Publication; 2009.

86. Desai RA, Maciejewski PK, Dausey DJ, Caldarone BJ, Potenza MN. Health correlates of recreational gambling in older adults. Am J Psychiatry. 2004;161(9):1672-9.

87. Foottit J, Anderson D. Associations between perception of wellness and health-related quality of life, comorbidities, modifiable lifestyle factors and demographics in older Australians. Australas J Ageing. 2012;31(1):22-7.

88. Shaffer HJ, Korn DA. Gambling and related mental disorders: a public health analysis. Annu Rev Public Health. 2002;23(1):171-212.

89. Vaillant GE, Mukamal K. Successful Aging. Am J Psychiatry. 2001;158(6):839-47.

90. Raisamo S, Halme J, Murto A, Lintonen T. Gambling-related harms among adolescents: a population-based study. J Gambl Stud. 2013;29(1):151-9.

91. Ranabir S, Reetu K. Stress and hormones. Indian J Endocrinol Metab. 2011; 15(1):18-22.

92. Pilver CE, Potenza MN. Increased incidence of cardiovascular conditions among older adults with pathological gambling features in a prospective study. J Addict Med. 2013;7(6):387-93.

93. Black DW, Shaw M, McCormick B, Allen J. Pathological gambling: relationship to obesity, self-reported chronic medical conditions, poor lifestyle choices, and impaired quality of life. Compr Psychiatry. 2013;54(2):97-104.

94. Desai RA, Desai MM, Potenza MN. Gambling, health, and age: data from the national epidemiologic survey on alcohol and related conditions. Psychol Addict Behav. 2007;21(4):431-40.

95. Cowlishaw S, Merkouris S, Chapman A, Radermacher H. Pathological and problem gambling in substance use treatment: a systematic review and meta-analysis. J Subst Abus Treat. 2014;46(2):98-105.

96. McGrath DS, Barrett SP. The comorbidity of tobacco smoking and gambling: a review of the literature. Drug Alcohol Rev. 2009;28(6):676-81.

97. Assanangkornchai S, McNeil EB, Tantirangsee N, Kittirattanapaiboon P. Gambling disorders, gambling type preferences, and psychiatric comorbidity among the Thai general population: results of the 2013 national mental health survey. J Behav Addict. 2016;5(3):410-8.

98. Manning V, Dowling NA, Lee S, Rodda S, Garfield JBB, Volberg R, et al. Problem gambling and substance use in patients attending community mental health services. J Behav Addict. 2017;6(4):678-88.
99. Scholes-Balog KE, Hemphill SA. Relationships between online gambling, mental health, and substance use: a review. Cyberpsychol Behav Soc Netw. 2012;15(12):688-92.

100. Afifi TO, Nicholson R, Martins SS, Sareen J. A longitudinal study of the temporal relation between problem gambling and mental and substance use disorders among young adults. Can J Psychiatr. 2016;61(2):102-11.

101. Wong PW, Cheung DY, Conner KR, Conwell Y, Yip PS. Gambling and completed suicide in Hong Kong: A review of coroner court files. Prim Care Companion J Clin Psychiatry. 2010;12(6):PCC.09m00932. https://doi.org/10.4 088/PCC.09m00932blu.

102. Wong P, Chan W, Conwell Y, Conner K, Yip P. A psychological autopsy study of pathological gamblers who died by suicide. J Affect Disord. 2010; 120(1-3):213-6.

103. Moghaddam JF, Yoon G, Dickerson DL, Kim SW, Westermeyer J. Suicidal ideation and suicide attempts in five groups with different severities of gambling: findings from the national epidemiologic survey on alcohol and related conditions. Am J Addict. 2015;24(4):292-8.

104. Thon N, Preuss UW, Pölzleitner A, Quantschnig B, Scholz H, Kühberger A, et al. Prevalence of suicide attempts in pathological gamblers in a nationwide Austrian treatment sample. Gen Hosp Psychiatry. 2014;36(3):342-6.

105. Wong P, Kwok N, Tang J, Blaszczynski A, Tse S. Suicidal ideation and Familicidal-suicidal ideation among individuals presenting to problem gambling services. Crisis. 2014;35(4):219-32.

106. Newman SC, Thompson AH. The association between pathological gambling and attempted suicide: findings from a National Survey in Canada. Can J Psychiatr. 2007;52(9):605-12.

107. Battersby M, Tolchard B, Scurrah M, Thomas L. Suicide ideation and behaviour in people with pathological gambling attending a treatment service. Int J Ment Heal Addict. 2006;4(3):233-46.

108. Ledgerwood DM, Steinberg MA, Wu R, Potenza MN. Self-reported gambling-related suicidality among gambling helpline callers. Psychol Addict Behav. 2005;19(2):175-83.

109. Nower L, Gupta R, Blaszczynski A, Derevensky J. Suicidality and depression among youth gamblers: a preliminary examination of three studies. Int Gambl Stud. 2004;4(1):69-80.

110. Cook S, Turner NE, Ballon B, Paglia-Boak A, Murray R, Adlaf EM, et al. Problem gambling among Ontario students: associations with substance abuse, mental health problems, suicide attempts, and delinquent Behaviours. J Gambl Stud. 2015;31(4):1121-34.

111. Downs C. Selling hope: gambling entrepreneurs in Britain 1906-1960. J Bus Res. 2015;68(10):2207-13.

112. Basham P, Luik J. The social benefits of gambling. Econ Aff. 2011;31(1):9-13.

113. Williams R, Belanger $Y$, Arthur J. Gambling in Alberta: history, current status and socioeconomic impacts. Edmonton: Final Report submitted to the Alberta Gaming Research Institute; 2011.

114. Kalischuk RG, Nowatzki N, Cardwell K, Klein K, Solowoniuk J. Problem gambling and its impact on families: a literature review. Int Gambl Stud. 2006;6(1):31-60.

115. Shaw M, Forbush K, Schlinder J, Rosenman E, Black D. The effect of pathological gambling on families, marriages, and children. CNS Spectr. 2007;12(8):615-22.

116. Dowling NA, Rodda SN, Lubman DI, Jackson AC. The impacts of problem gambling on concerned significant others accessing web-based counselling. Addict Behav. 2014;39(8):1253-7.

117. Holdsworth L, Nuske E, Tiyce M, Hing N. Impacts of gambling problems on partners: partners' interpretations. Asian J Gambl Issues Public Health. 2013;3(1):11.

118. Dickson-Swift VA, James EL, Kippen S. The experience of living with a problem gambler: spouses and partners speak out. J Gambl Issues. 2005; 13(13). https://doi.org/10.4309/jgi.2005.13.6.

119. Holdsworth L, Nuske E, Breen H. All mixed up together: Women's experiences of problem gambling, comorbidity and co-occurring complex needs. Int J Ment Heal Addict. 2013;11:315-28.

120. Svensson J, Romild U, Shepherdson E. The concerned significant others of people with gambling problems in a national representative sample in Sweden - a 1 year follow-up study. BMC Public Health. 2013;13(1):1087.

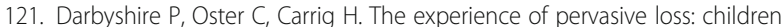
and young people living in a family where parental gambling is a problem. J Gambl Stud. 2001;17(1):23-45.

122. Darbyshire P, Oster C, Carrig H. Children of parent(s) who have a gambling problem: a review of the literature and commentary on research approaches. Health Soc Care Community. 2001;9(4):185-93. 
123. Hodgins DC, Shead NW, Makarchuk K. Relationship satisfaction and psychological distress among concerned significant others of pathological gamblers. J Nerv Ment Dis. 2007;195(1):65-71.

124. Black DW, Shaw MC, McCormick BA, Allen J. Marital status, childhood maltreatment, and family dysfunction: a controlled study of pathological gambling. J Clin Psychiatry. 2012;73(10):1293-7.

125. Afifi TO, Brownridge DA, MacMillan H, Sareen J. The relationship of gambling to intimate partner violence and child maltreatment in a nationally representative sample. J Psychiatr Res. 2010;44(5):331-7.

126. Anderson A, Sisask M, Värnik A. Familicide and suicide in a case of gambling dependence. J Forens Psychiatry Psychol. 2011;22(1):156-68.

127. Korman LM, Collins J, Dutton D, Dhayananthan B, Littman-Sharp N, Skinner W. Problem gambling and intimate partner violence. J Gambl Stud. 2008; 24(1):13-23.

128. Dowling N, Suomi A, Jackson A, Lavis T, Patford J, Cockman S, et al. Problem gambling and intimate partner violence. Trauma Violence Abuse. 2016;17(1):43-61.

129. Keen B, Pickering D, Wieczorek M, Blaszczynski A. Problem gambling and family violence in the Asian context: a review. Asian J Gambl Issues Public Health. 2015;5(1):3.

130. Liao MS. Intimate partner violence within the Chinese community in san Francisco: problem gambling as a risk factor. J Fam Violence. 2008;23(8):671.

131. Suomi A, Jackson AC, Dowling NA, Lavis T, Patford J, Thomas SA, et al. Problem gambling and family violence: family member reports of prevalence, family impacts and family coping. Asian J Gambl Issues Public Health. 2013;3(1):13.

132. Kuoppamäki S-M, Kääriäinen J, Lind K. Examining gambling-related crime reports in the National Finnish police register. J Gambl Stud. 2014;30(4):967-83.

133. Salonen $A H$, Castrén S, Alho H, Lahti T. Concerned significant others of people with gambling problems in Finland: a cross-sectional population study. BMC Public Health. 2014;14(1):398.

134. Hope J, Havir L. You bet they're having fun!: older Americans and casino gambling. J Aging Stud JAl. 2002;16(2):177-97.

135. Hardoon KK, Gupta R, Derevensky JL. Psychosocial variables associated with adolescent gambling. Psychol Addict Behav. International Centre for Youth Gambling Problems and High-Risk Behaviors, McGill University, Montreal, Québec, Canada. 2004;18(2):170-9.

136. Kristiansen S, Trabjerg MC, Reith G. Learning to gamble: early gambling experiences among young people in Denmark. J Youth Stud. 2015;18(2):133-50.

137. Wenzel HG, Øren A, Bakken IJ. Gambling problems in the family - a stratified probability sample study of prevalence and reported consequences. BMC Public Health BioMed Central. 2008:8(1):412.

138. Patford J. For worse, for poorer and in ill health: how women experience, understand and respond to a partner's gambling problems. Int J Ment Heal Addict Springer-Verlag. 2009;7(1):177-89.

139. Salonen AH, Alho H, Castren S. Gambling frequency, gambling problems and concerned significant others of problem gamblers in Finland: crosssectional population studies in 2007 and 2011. Scand J Public Health. 2015; 43(3):229-35.

140. Oei TP, Raylu N. Familial influence on offspring gambling: a cognitive mechanism for transmission of gambling behavior in families. Psychol Med. 2004;34(7):1279-88.

141. Dowling N, Jackson A, Thomas S, Frydenberg E. Children at risk of developing problem gambling. Melbourne: Gambling Research Australia; 2010.

142. Black DW, Coryell W, Crowe R, McCormick B, Shaw M, Allen J. Suicide ideations, suicide attempts, and completed suicide in persons with pathological gambling and their first-degree relatives. Suicide LifeThreatening Behav. 2015;45(6):700-9.

143. Vitaro F, Wanner B, Brendgen M, Tremblay RE. Offspring of parents with gambling problems: adjustment problems and explanatory mechanisms. J Gambl Stud. 2008;24(4):535-53.

144. Lim SH, Zhang L. Does casino development have a positive effect on economic growth? Growth Chang. 2017;48(3):409-34.

145. Elliott DS, Navin JC. Has riverboat gambling reduced state lottery revenue? Public Financ Rev. 2002;30(3):235-47.

146. Walker $D$, Jackson J. The effect of legalized gambling on state goverment revenue. Contemp Econ Policy. 2011;29(1):101-14.

147. Honoré PA, Simoes EJ, Moonesinghe R, Wang X, Brown L. Evaluating the ecological association of casino industry economic development on community health status: a natural experiment in the Mississippi delta region. J Public Health Manag Pract. 2007;13(2):214-22.
148. Abdel-Ghany M, Sharpe DL. Lottery expenditures in Canada: regional analysis of probability of purchase, amount of purchase, and incidence. Fam Consum Sci Res J. 2001;30(1):64-78.

149. Spectrum Gaming Group. Gambling in Connecticut: analyzing the economic and social impacts. Linwood: Spectrum Gaming Group; 2009.

150. Conner TW, Taggart WA. The impact of gaming on the Indian nations in New Mexico. Soc Sci Q. 2009;90(1):50-70.

151. Wan YKP, Li XC, Kong WH. Social impacts of casino gaming in Macao: a qualitative analysis. Tourism. 2011;59(1):63-82.

152. Mangham C, Carney G, Burnett S, Williams L. Socioeconomic impacts of new gaming venues in four British Columbia lower mainland communities: final report. Victoria: Blue Thorn Research and Analysis Group; 2007.

153. Anders GC. Native American casino gambling in Arizona: a case study of the fort McDowell reservation. J Gambl Stud. 1996;12(3):253-67.

154. Australian Institute for Gambling Research. Report of the first year of the study into the social and economic impact of the introduction of gaming machines to Queensland clubs and hotels. Brisbane: The Department; 1995.

155. Bybee S, Aguero J. The hospitality industry's impact on the state of Nevada: a summary \& review. Gaming Res Rev J. 2000;5(2):27-31.

156. Blevins A, Jensen K. Gambling as a community development quick fix. Ann Am Acad Pol Soc Sci. 1998;556(1):109-23.

157. Smeral E. Economic aspects of casino gaming in Austria. J Travel Res. 1998; 36(4):33-9.

158. D'Hauteserre A-M. Foxwoods casino resort: an unusual experiment in economic development. Econ Geogr. 2008;74(s1):112-21.

159. Aasved MJ, Schaefer JM, Merila K. Legalized gambling and its impacts in a Central Minnesota vacation community: a case study. J Gambl Stud. 1995; 11(2):137-63.

160. Cotti $C$. The effect of casinos on local labor markets: a county level analysis. J Gambl Bus Econ. 2008;2(2):17-41.

161. Fenich GG, Hashimoto K. Perceptions of cannibalization: what is the real effect of casinos on restaurants? Gaming Law Rev. 2004;8(4):247-59.

162. Walker DM, Jackson JD. New goods and economic growth: evidence from legalized gambling. Rev Reg Stud. 1998;28(2):47-70.

163. Dense J. The socioeconomic impact of gaming in the Virgin Islands. Gaming Law Rev. 2004:8(3):175-88.

164. Siegel D, Anders G. Public policy and the displacement effects of casinos: a case study of riverboat gambling in Missouri. J Gambl Stud. 1999;15(2):105-21.

165. Anders G, Siegel D, Yacoub M. Does Indian casino gambling reduce state revenues? Evidence from Arizona. Contemp Econ Policy. 1998;16(3):347-55.

166. Cartee C, Gordon G. The gaming industry's effect on economic activity of the Mississippi Gulf Coast. Econ Dev Rev. 1997;15(2):47-50.

167. Koo J, Rosentraub MS, Horn A. Rolling the dice? Casinos, tax revenues, and the social costs of gaming. J Urban Aff. 2007;29(4):367-81.

168. Victorian Competition and Efficiency Commission. Counting the Cost: Inquiry into the Costs of Problem Gambling. final report, December; 2012.

169. Aasved MJ, Laundergan JC. Gambling and its impacts in a northeastern Minnesota community: an exploratory study. J Gambl Stud. 1993;9(4):301-19.

170. Fenelon JV. Indian gaming: traditional perspectives and cultural sovereignty. Am Behav Sci. 2006;50(3):381-409.

171. Peacock TD, Day PA, Peacock RB. At what cost? The social impact of American Indian gaming. J Health Soc Policy. 1999;10(4):23-34.

172. Grun L, McKeigue P. Prevalence of excessive gambling before and after introduction of a national lottery in the United Kingdom: another example of the single distribution theory. Addiction. 2000;95(6):959-66.

173. Tong HHY, Chim D. The relationship between casino proximity and problem gambling. Asian J Gambl Issues Public Health. 2013;3(1):2.

174. Lang KB, Omori M. Can demographic variables predict lottery and Parimutuel losses? An Empirical Investigation. J Gambl Stud. 2009;25(2):171-83.

175. Castrén S, Kontto J, Alho H, Salonen AH. The relationship between gambling expenditure, socio-demographics, health-related correlates and gambling behaviour-a cross-sectional population-based survey in Finland. Addiction. 2018;113(1):91-106.

176. Beckert J, Lutter M. The inequality of fair play: lottery gambling and social stratification in Germany. Eur Sociol Rev. 2009;25(4):475-88.

177. Salonen A, Kontto J, Alho H, Castrén S. Suomalaisten rahapelikulutus keneltä rahapeliyhtiöiden tuotot tulevat? Yhteiskuntapolitiikka. 2017;82(5): 549-59.

178. Rockloff MJ, Browne M, Russell AMT, Merkouris SS, Dowling NA. A quantification of the net consumer surplus from gambling participation. J Gambl Stud Springer US. 2019;29:1-16. 
179. Laursen B, Plauborg R, Ekholm O, Larsen CVL, Juel K. Problem gambling associated with violent and criminal behaviour: a Danish population-based survey and register study. J Gambl Stud. 2016;32(1):25-34.

180. Stokowski PA. Crime patterns and gaming development in rural Colorado. J Travel Res. 1996;34(3):63-9.

181. Cotti CD, Walker DM. The impact of casinos on fatal alcohol-related traffic accidents in the United States. J Health Econ. 2010;29(6):788-96.

182. Reece W. Casinos, hotels, and crime. Contemp Econ Policy. 2010;28(2):145-61.

183. Spel S. The cost of gambling. An analysis of the socio-economic costs resulting from problemgambling in Sweden; 2009.

184. Thorley C, Stirling A, Huynh E. Cards on the table: the cost to government associated with people who are problem gamblers in Brita; 2016.

185. Dyall L. Gambling, social disorganisation and deprivation. Int J Ment Heal Addict. 2007;5(4):320-30.

186. Collins D, Lapsley H. The social costs and benefits of gambling: an introduction to the economic issues. J Gambl Stud. 2003;19(2):123-48.

187. Momper SL, Dennis MK. American Indian women report on the community impact of a tribal casino. Race Soc Probl. 2010;2(1):59-68.

188. Vander Bilt J, Vander DHH, Pandav R, Shaffer HJ, Ganguli M. Gambling participation and social support among older adults: a longitudinal community study. J Gambl Stud. 2004;20(4):373-89.

189. LaPlante DA, Shaffer HJ. Understanding the influence of gambling opportunities: expanding exposure models to include adaptation. Am J Orthop. 2007:77(4):616-23.

190. Shaffer HJ, Hall MN, Vander BJ. Estimating the prevalence of disordered gambling behavior in the United States and Canada: a research synthesis. Am J Public Health. Division on Addictions, Harvard Medical School, Boston, Mass. 02115-5729, USA. 1999:89(9):1369-76.

191. Abbott M, Stone CA, Billi R, Yeung K. Gambling and problem gambling in Victoria, Australia: changes over 5 years. J Gambl Stud. Springer US. 2016; 32(1):47-78

192. Abbott M, Romild U, Volberg R. Gambling and problem gambling in Sweden: changes between 1998 and 2009. J Gambl Stud. 2014:30(4):985-99.

\section{Publisher's Note}

Springer Nature remains neutral with regard to jurisdictional claims in published maps and institutional affiliations.

Ready to submit your research? Choose BMC and benefit from:

- fast, convenient online submission

- thorough peer review by experienced researchers in your field

- rapid publication on acceptance

- support for research data, including large and complex data types

- gold Open Access which fosters wider collaboration and increased citations

- maximum visibility for your research: over $100 \mathrm{M}$ website views per year

At $\mathrm{BMC}$, research is always in progress.

Learn more biomedcentral.com/submissions 